\title{
Rural electrification using overhead HVDC transmission lines
}

\section{Leon Chetty}

Nelson ljumba

HVDC Centre, University of KwaZulu-Natal, South Africa

\begin{abstract}
One of mankind's greatest modern challenges is poverty alleviation. The provision of electricity can greatly assist in this regard. The tapping of small amounts of power from an HVDC transmission line represents a solution to this problem especially in rural areas. This paper analyses the dynamic characteristics of a parallel-cascaded tapping station. The results obtained clearly indicate that the parallel-cascaded tapping station proves to be a viable solution to tapping small amounts of power from an HVDC transmission line.
\end{abstract}

Keywords: rural electrification, HVDC transmission lines, voltage source inverter

\section{Introduction}

The provision of electricity greatly enhances the quality of life in developing countries in Southern Africa. It helps promote people's expectations and motivations, thus assisting in education. Most importantly, it helps in retarding the migration of people from rural areas to cities and increases the opportunities for income generation and employment in those countries. Electricity also assists in environmental preservation of forests and trees, which are currently being, cut down, for fuel, to compensate for the lack of electricity and other energy sources in rural areas (Khatib, 1998). Provision of electricity supplies is essential for developing countries in their effort to overcome poverty, which is the main challenge to mankind in this century.

Orthodox methods for the provision of electricity supplies, such as a central power station with a transmission and distribution network, which is ideal in industrial countries and urban areas, may not be the most economical means of providing electricity supplies in developing countries, particularly in rural areas where the demand per customer is only a small fraction of a kilowatt (Khatib, 1998). Mobilizing of capital and developing of new technologies is necessary in supplying power to these rural areas.

In the Southern African context, there are large amounts of hydro power in Central Africa, in countries such as the Democratic Republic of Congo, whereas the major load centres are in the Southern African region. Therefore, high voltage direct current (HVDC) transmission is likely to be the most economical means to transmit these large quantities of energy to the Southern African region. HVDC transmission does offer technical and economical advantages over HVAC (high voltage alternating current) transmission for long distances. However, HVDC transmission does suffer a significant disadvantage compared to high voltage alternating current (HVAC) transmission, with regard to tapping off power from transmission lines. It has not been proven to be economically and technically feasible to tap off small amounts of power from HVDC transmission lines. This is a substantial drawback considering that most HVDC transmission lines pass over many rural communities that have little or no access to electricity.

Although tapping of small amounts of power from HVDC transmission lines has been the focus of many researchers (Aghaebrahimi \& Menzies, 1997; Aghaebrahimi \& Menzies, 1998; Aredes et. al., 2001; Aredes et. al., 2002; Bahrman, 1995; Ekstrom \& Lamell, 1991; Lamm et. al., 1963; Lima et. al., 1991; Turanli et. al., 1989; Zhao \& Irvani, 1994), no successful implementation of the concept has been published to date. The main reasons for the non-application of this concept are that:

The rural villages, into which the power will be tapped, usually have weak $\mathrm{AC}$ systems, which have 
few or no rotating machine loads.

Previously only line-commutated inverters, which required an $\mathrm{AC}$ source for its operation, were available. Therefore, the use of these devices did not make the small power tapping station feasible, since synchronous condensers were required.

With the rapid development of gate-turn off switches, such as Insulated Gate Bipolar Transistors (IGBTs), the voltage source inverter (VSI) received considerable interest because it did not require an $\mathrm{AC}$ source to commutate against, and it could easily invert power into a passive load. The issue currently at hand is whether the tapping station should be connected in series or in parallel to the HVDC transmission line. All of the recent publications (Aghaebrahimi \& Menzies, 1997; Aghaebrahimi \& Menzies, 1998; Aredes et. al., 2001; Aredes et. al., 2002) have considered the series-tapping concept to be more superior based on the qualitative assessment. No formal quantitative investigation has been undertaken to establish which concept, either the series or the parallel concept, is more superior.

Although the research by (Aredes et. al., 2001; Aredes et. al., 2002) has shown satisfactory results for one series tap connected at the middle of the HVDC transmission line, this author does not recommend this technique for the African context, since an HVDC transmission line transporting power from Central Africa to Southern Africa will be at least $3000 \mathrm{~km}$ long. Therefore, it is very likely that the HVDC transmission line will pass more than 2 (may be greater than 10) rural communities, spaced along the HVDC transmission line. Hence, it would not be economically feasible to have one series tap at the middle of the HVDC transmission line supplying power to all these communities. Further, a series tap causes a volt drop on the HVDC transmission line, which increases the main rectifier and inverter thyristor valve losses and stresses (Ekstrom \& Lamell, 1991).

This paper presents the development of a system for multiple power tap offs from HVDC transmission lines for rural applications.

\section{Methodology}

Given the large differences between the HVDC transmission and rural distribution voltage level, the tap off was achieved in two stages. Firstly, a novel DC-to-DC converter was designed for connection in parallel with the HVDC transmission line and step down the high $\mathrm{DC}$ voltage to a lower $\mathrm{DC}$ voltage. Secondly, a voltage source inverter was used to invert the lower DC voltage into a three-phase voltage.

\subsection{Voltage source converter}

Voltage Source Converters (VSC) represents economical solutions to the most challenging, modern day requirements on the power transmission and distribution systems. The most important feature is feeding power to AC systems with low short circuit ratio or even passive networks with no local power generation.

To minimize the fixed cost of the tapping station, a six-pulse VSI as opposed to a twelve-pulse VSI was chosen. This six-pulse VSI circuit configuration is shown in Figure 1.

To simplify the analysis, the model of the converter transformer was not included. To compensate for the converter transformer, the load was connected in a delta configuration, which was the same way the winding on the converter side of the transformer was connected. The function of the delta configuration in this application was to eliminate the DC component of the phase voltage.

\subsection{Step-down DC-to-DC converter}

To reduce the voltage stress on the VSI IGBT valves, the concept of a novel DC-to-DC converter was explored to step down the high transmission line DC voltage down to a lower voltage. In this section, the transmission line $\mathrm{DC}$ voltage is modelled as a constant DC source.

The requirements of the $\mathrm{DC}$-to-DC converter are aligned with the requirements of the main tapping station. These requirements are restated here for clarity. The small power parallel tapping station will

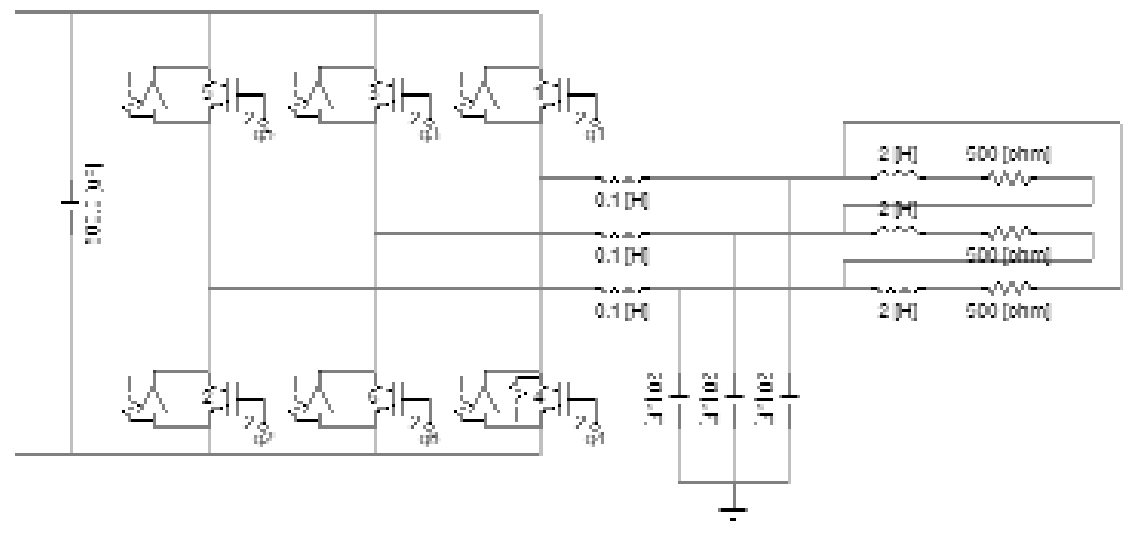

Figure 1: Six pulse VSI with Delta connected load 
be developed to meet the following requirements:

The fixed cost of the tapping station will be strongly constrained. One of the ways of meeting this requirement is to reduce the amount of equipment connected directly to the HVDC transmission line. This should be done not only to due reducing economics, but also to increase reliability.

The tapping station must have a negligible impact on the HVDC transmission system.

The tapping station control system should not interfere with the main HVDC control system and should be ideally local or else hardware cost will increase.

A buck, step-down, converter, shown in Figure 2 , produces a lower average output $\mathrm{DC}$ voltage than the applied DC input voltage.
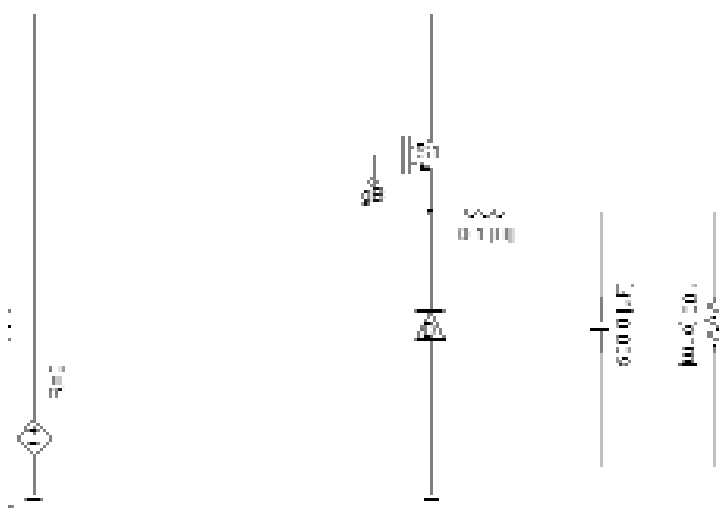

Figure 2: Buck converter

The output voltage fluctuations are diminished by using a low-pass filter, consisting of an inductor and capacitor. The corner frequency $\mathrm{f}_{\mathrm{c}}$ of the lowpass filter is selected to be much lower than the switching frequency, thus essentially eliminating the switching frequency ripple in the output voltage.
The corner frequency is calculated from:

$$
f_{c}=\frac{1}{2 \mathrm{p} \sqrt{L C}}
$$

For the HVDC transmission line tapping off application, the switch frequency was chosen to minimize switching losses and thus was selected to be $750 \mathrm{~Hz}$. The values chosen for $\mathrm{L}$ and $\mathrm{C}$ were based on equation (1). To evaluate the effectiveness of the Buck converter to step-down the high transmission line DC voltage and tap small amounts of power from HVDC transmission lines, the Buck converter, shown in Figure 2, was simulated in PSCAD/EMTDC. The results of the simulation are shown Figure 3. The switch $S_{1}$ is de-blocked at 0.1 seconds.

During steady-state operation, the switch $\mathrm{S}_{1}$ periodically blocked the source voltage $(500 \mathrm{kV})$ to produce a regulated output voltage $(20 \mathrm{kV})$. The Buck converter demonstrated that it had the capability of stepping the HVDC transmission line voltage $(500 \mathrm{kV})$ down to a lower DC voltage $(20 \mathrm{kV})$. The Buck converter consisted of few high voltage components and its control system was completely local and did not require any communication with the main HVDC control system. The Buck converter was used as the DC-to-DC converter in the required parallel tapping station.

\section{Results}

The HVDC transmission line model used in this project was based on the CIGRE HVDC benchmark model (Szechtman, et. al., 1991) shown in Figure 4.

The DC system is rated at $500 \mathrm{kV}(\mathrm{DC}), 1000$ MW. The AC side systems are fairly weak; with short circuit ratios on the sending and receiving end systems of 2.5 and 2.35 with damping angles of $84^{\circ}$

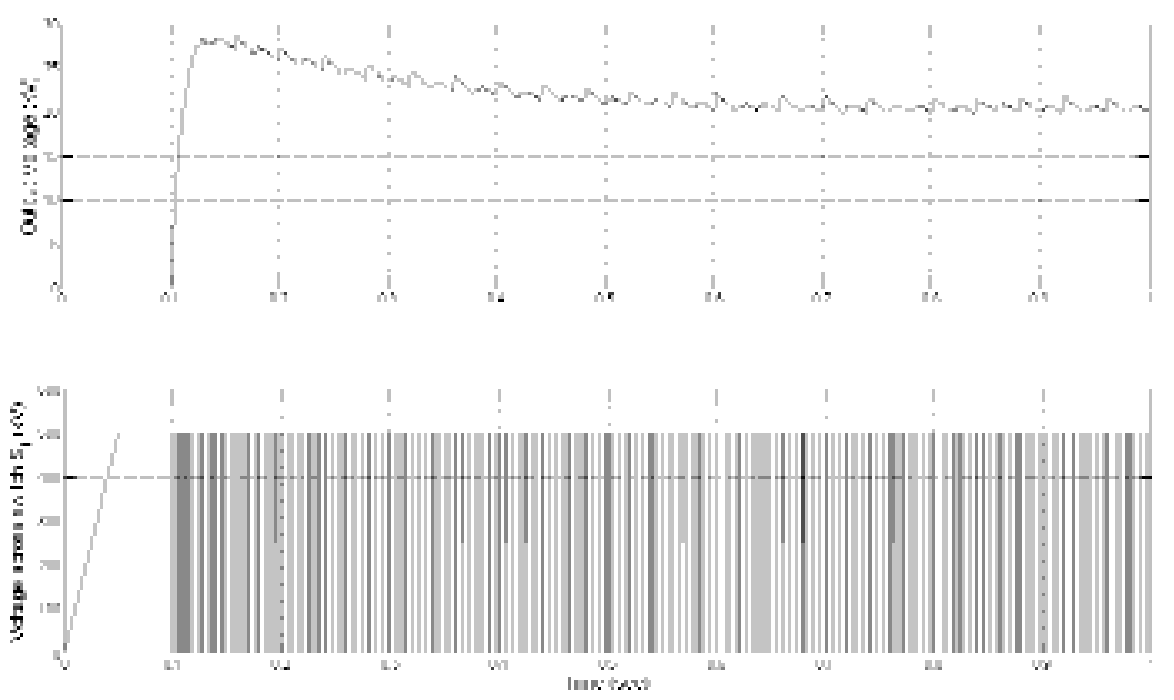

Figure 3: Simulation results for the Buck converter 


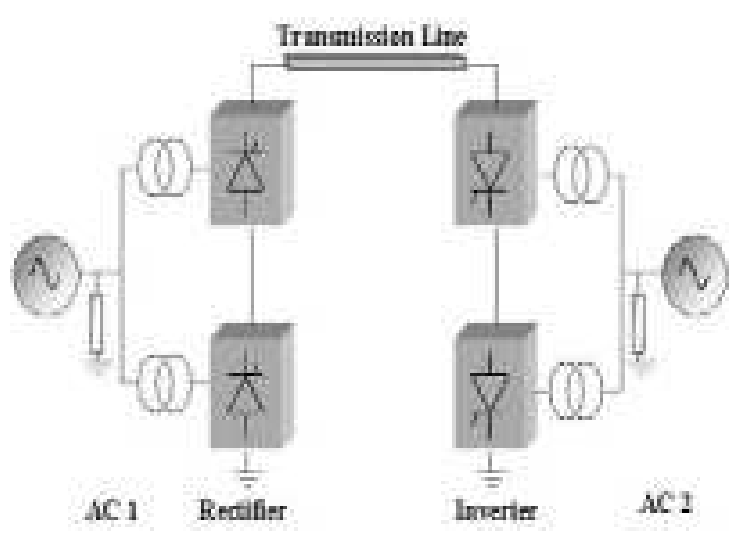

Figure 4: CIGRE HVDC benchmark model

and $75^{\circ}$. A detailed discussion on the model and its implementation in PSCAD/EMTDC can be found in (Szechtman, et. al., 1991).

As reference for evaluating the effect of the small power tapping station on an HVDC transmission line, some incidental simulations were conducted.

The HVDC system characteristics during startup of the HVDC converter terminals are displayed in Figure 5. The HVDC converter terminals are deblocked at 0.04 seconds. The HVDC system takes approximately 0.2 seconds to stabilize after the start-up of the HVDC converter terminals.

The HVDC system characteristics during a three-phase fault that occurs near the $\mathrm{AC}$ side of the rectifier terminal are displayed in Figure 6. The fault is solidly grounded. The fault occurs at $0.65 \mathrm{sec}-$ onds and last for 3 cycles.

The HVDC system takes approximately $0.6 \mathrm{sec}-$ onds to stabilize after the clearance of the fault. As a consequence of the HVDC transmission link, a three-phase fault occurring on the rectifier $\mathrm{AC}$ system results in a $0.3 \%$ overvoltage in the inverter $\mathrm{AC}$ system.
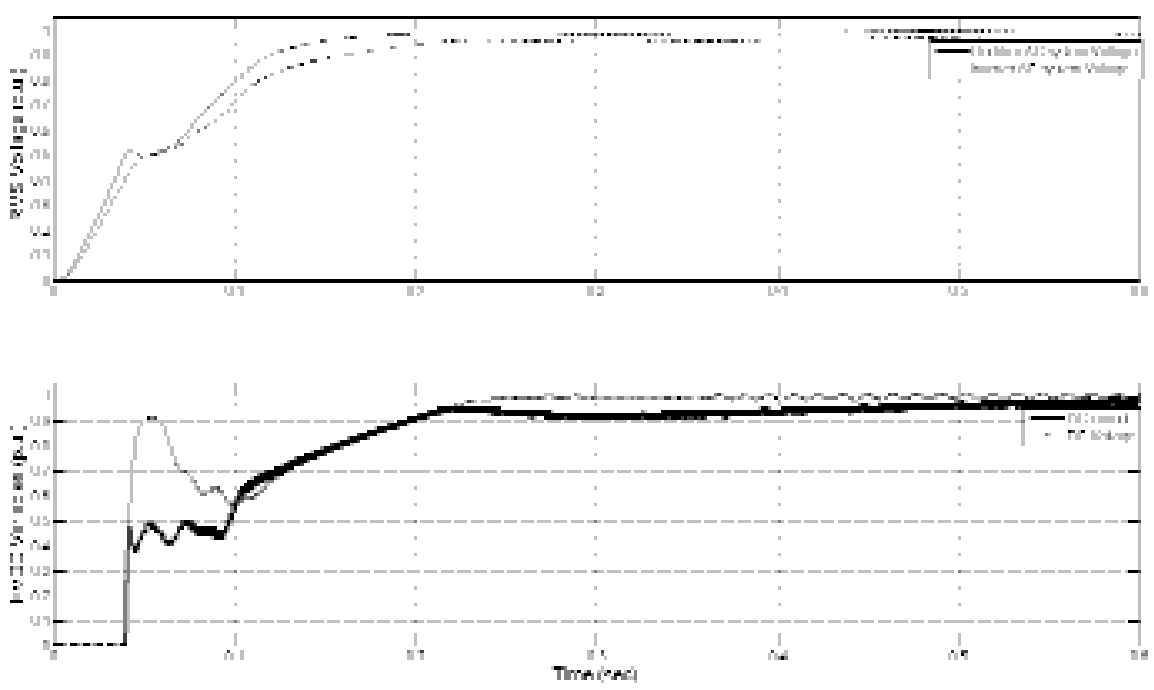

Figure 5: HVDC characteristics during start-up
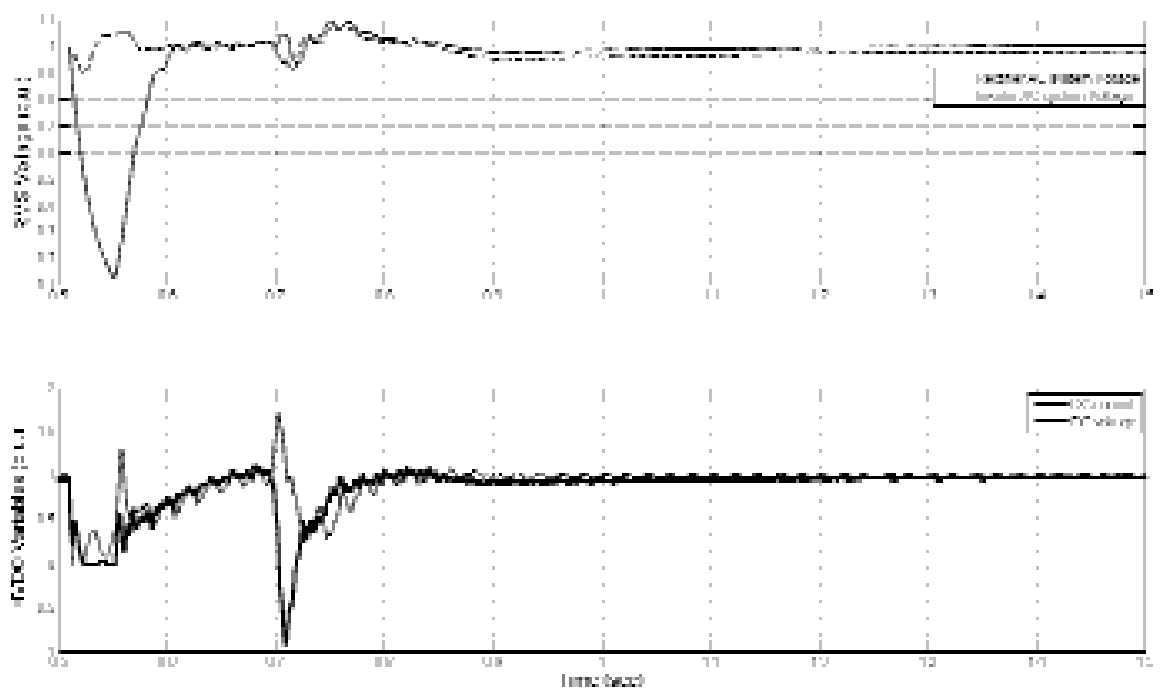

Figure 6: HVDC characteristics during rectifier three-phase fault 

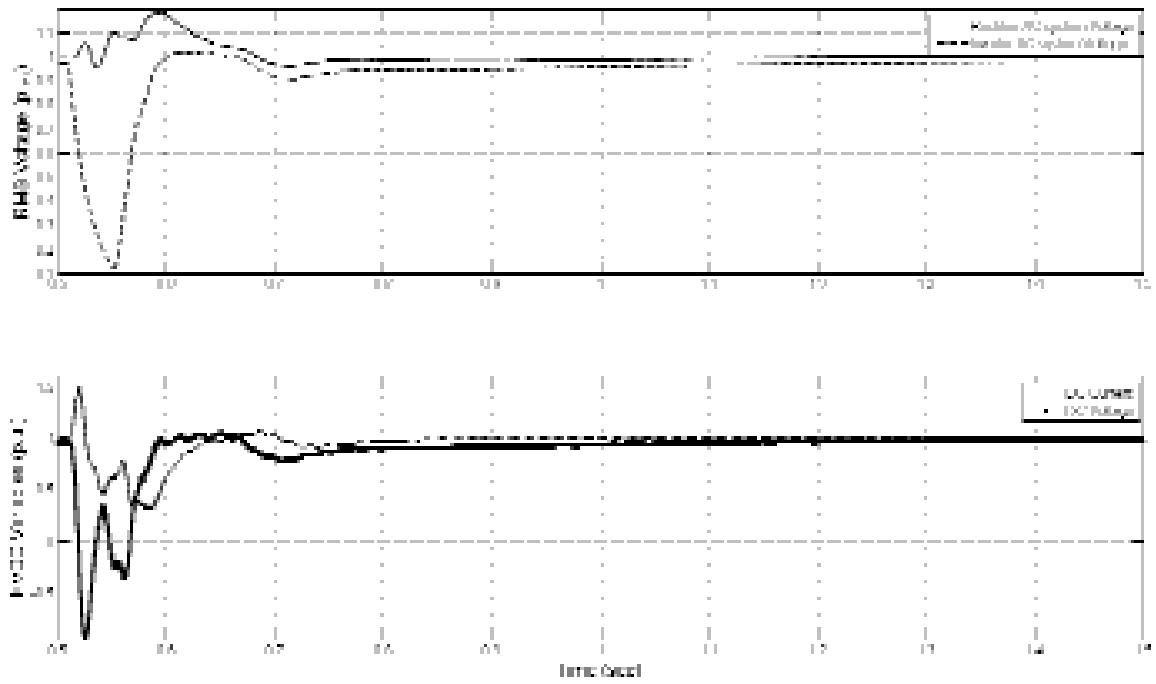

Figure 7: HVDC characteristics during inverter three-phase fault

The HVDC characteristics during a three-phase fault occurring in the inverter $\mathrm{AC}$ system are displayed in Figure 7. The fault is solidly grounded. The fault occurs at 0.65 seconds and last for 3 cycles. The HVDC system takes approximately 0.5 seconds to stabilize after the clearance of the fault as illustrated in Figure 7. As a consequence of the HVDC transmission link, a three-phase fault occurring on the inverter $\mathrm{AC}$ system results in a $0.2 \%$ overvoltage in the rectifier $\mathrm{AC}$ system.

The HVDC characteristic during an HVDC transmission line fault that occurs at the middle of the transmission line is displayed in Figure 8. The fault is solidly grounded. The fault occurs at 0.65 seconds and last for 3 cycles. During an HVDC transmission line fault, the rectifier changes its mode of operation and operates as an inverter so as to dissipate any energy stored in the transmission line as quick as possible. The HVDC system takes approximately 0.5 seconds to stabilize after the clearance of the fault as illustrated in Figure 8.

As a consequence of the HVDC transmission link, the transmission line fault results in a $0.3 \%$ voltage drop in the rectifier $\mathrm{AC}$ system and a $0.15 \%$ overvoltage in the inverter $\mathrm{AC}$ system.

\subsection{Effect of the tapping station on the HVDC transmission link}

The model of the tapping station was connected to the CIGRE HVDC transmission line model as depicted in Figure 9. This was done to quantify the effect that the cascaded parallel tapping station will have on the main HVDC transmission link.

\section{Start-up of the tapping station}

The HVDC transmission system was run up to steady-state and at 0.6 seconds, the Buck converter was connected to the HVDC transmission line. The
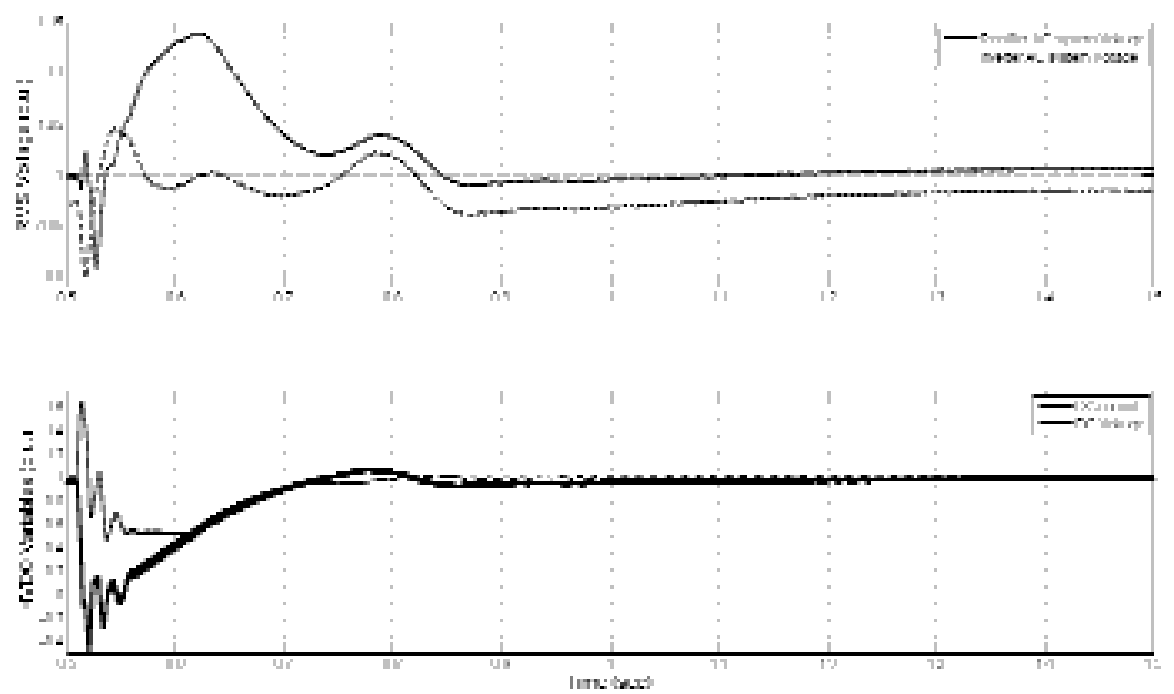

Figure 8: HVDC characteristics during HVDC transmission line fault 
capacitor Cs was initially uncharged, and therefore was allowed to charge up before the VSI was deblocked. The VSI was de-blocked at 0.65 seconds.
The results from the start-up of the tapping station are illustrated in Figure 10 and Figure 11.

The tapping station performance during start-up

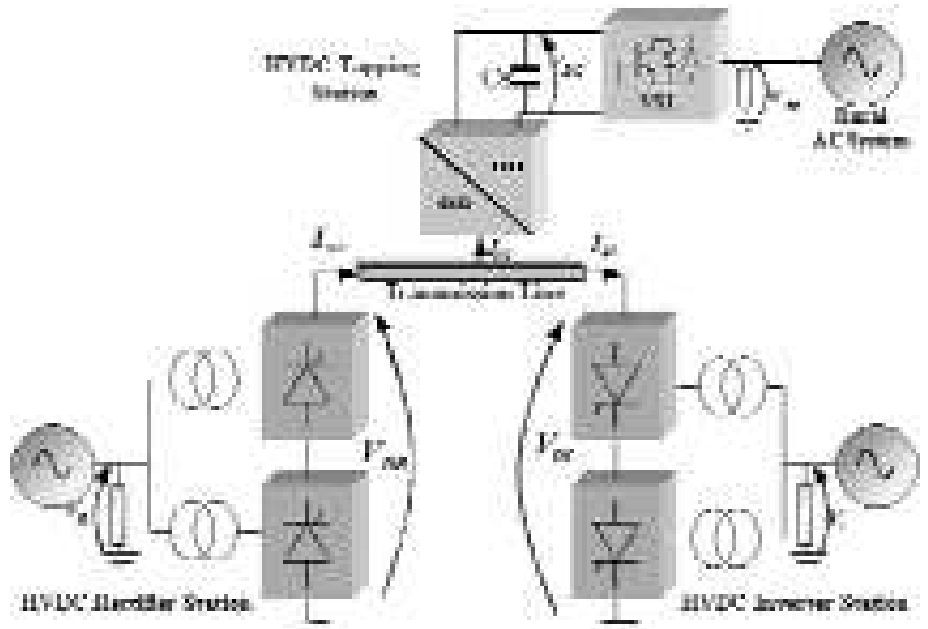

Figure 9: Small power tapping from an HVDC transmission line

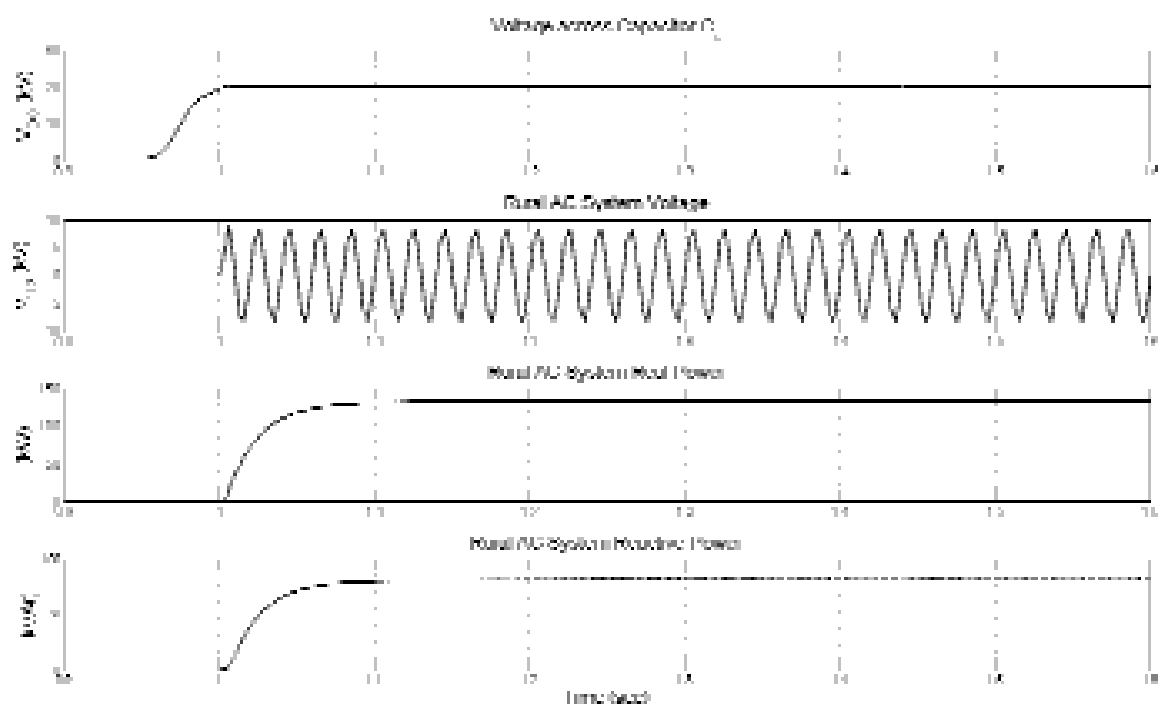

Figure 10: Tapping station characteristics during start-up
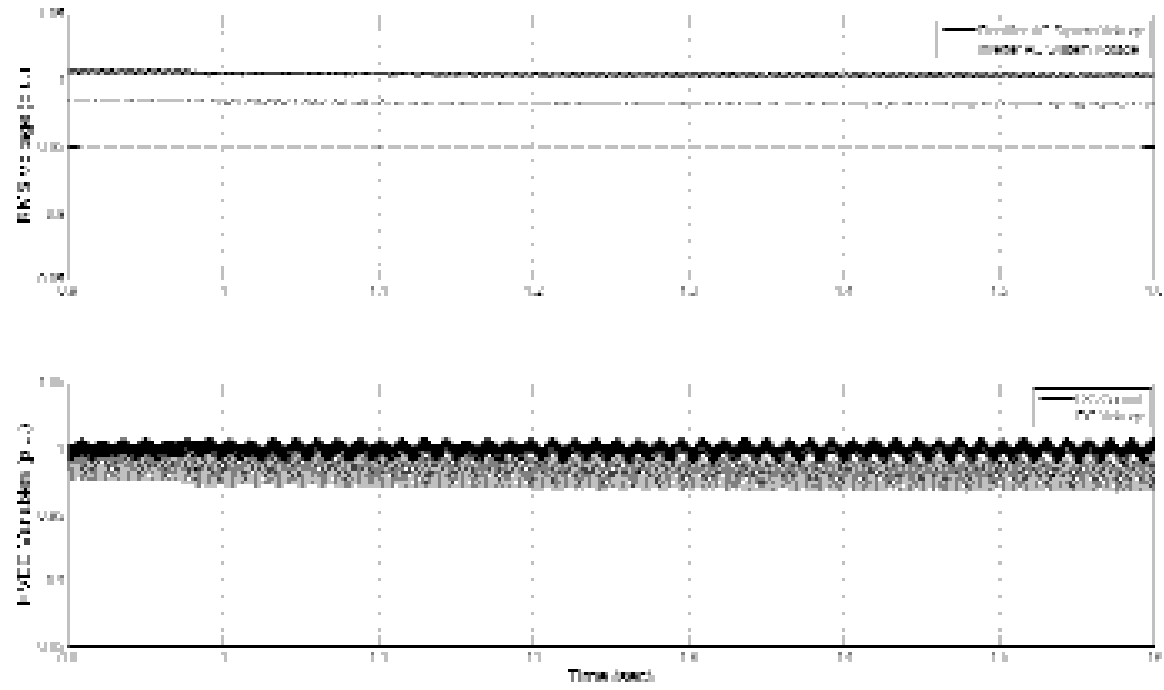

Figure 11: HVDC system characteristics during start-up 
is acceptable since the power is being fed to a passive load therefore the rural AC system takes a relatively long time (about 0.3 seconds) to stabilize.

The start-up of the tapping station had a negligible effect on the main HVDC transmission system, since there was only a slight drop in the HVDC voltages (less than $0.01 \%$ ) and power transfer (less than $0.2 \%$ ) and the HVDC system returns to its normal state within $45 \mathrm{msec}$

Rural AC system load change

To determine the effect that a load change in the rural AC system will have on the HVDC system, the rural load was doubled at 2 seconds and decreased to its nominal value at 3 seconds. The results are shown Figure 12 and Figure 13. A load change in the rural $\mathrm{AC}$ system has an unnoticeable effect on the HVDC system.
Rural AC system fault

A three-phase solidly earthed fault was applied to the rural AC system near the VSI, to determine the effect that a fault in the rural AC system will have on the main HVDC system. The fault was applied at 1.7 seconds and had duration of 0.04 seconds. The results of this simulation are shown in Figures 12 and 13. A three-phase fault in the rural AC system resulted in approximately $0.2 \%$ voltage drop in the HVDC transmission line voltages, and a $0.3 \%$ drop in the power transfer. The HVDC system takes 0.1 seconds to stabilize after the fault had cleared.

\section{Main rectifier $A C$ system fault}

A three-phase solidly earthed fault was applied to the rectifier $\mathrm{AC}$ system near the rectifier terminal, to determine the effect that a fault in the main rectifier AC system will have on the tapping station and the
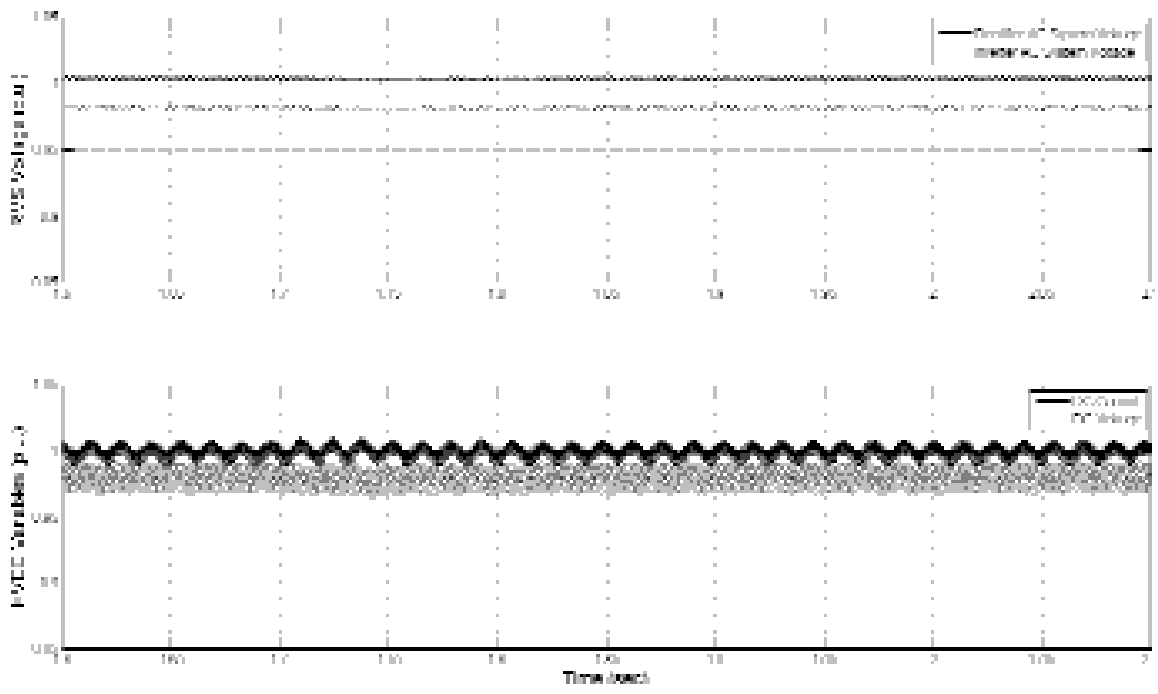

Figure 12: HVDC characteristics during a rural AC system load change
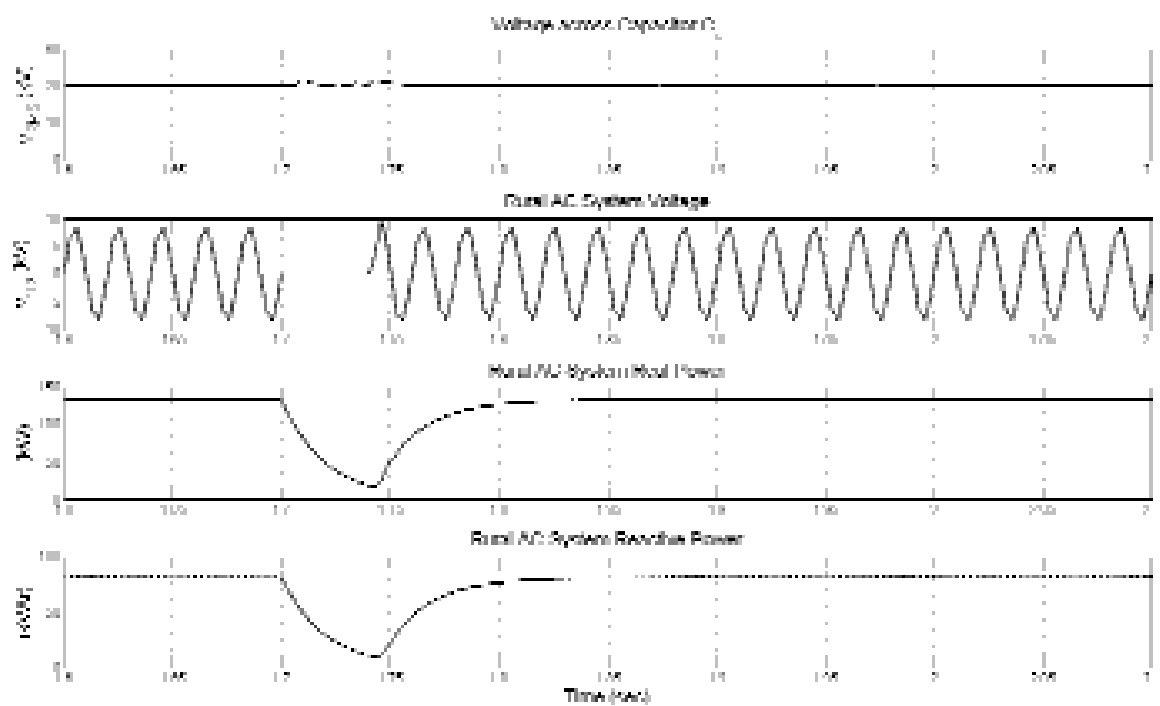

Figure 13: Tapping station characteristics during a rural AC system load change 

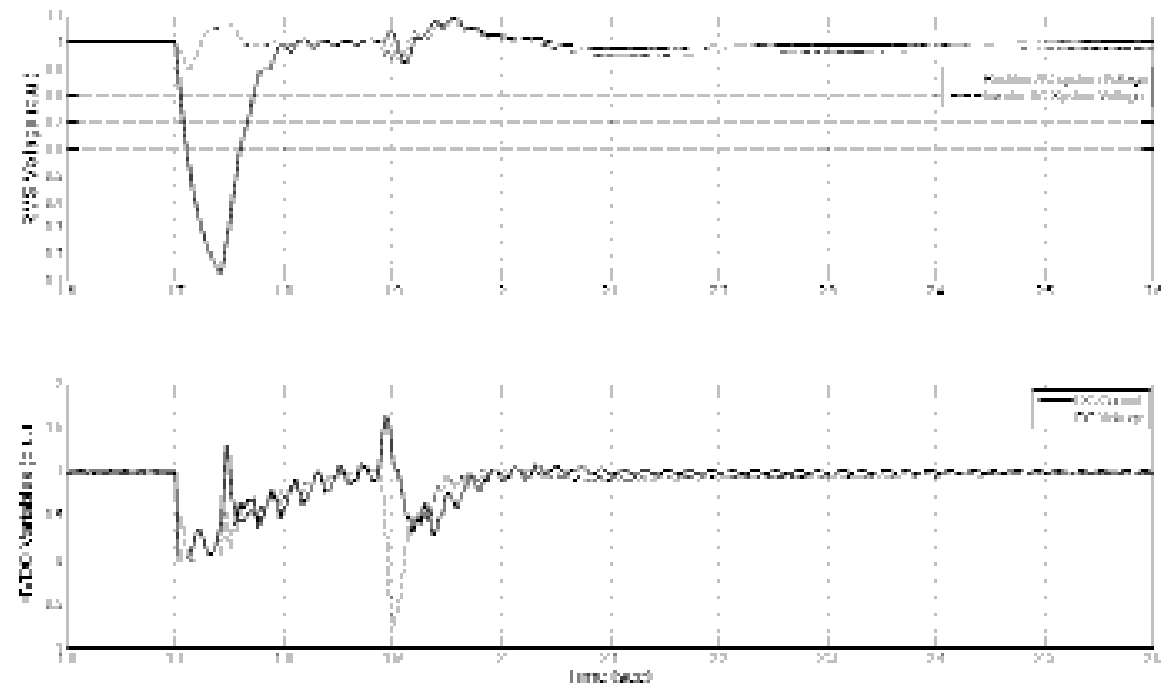

Figure 14: HVDC characteristics during a rural AC system three-phase fault
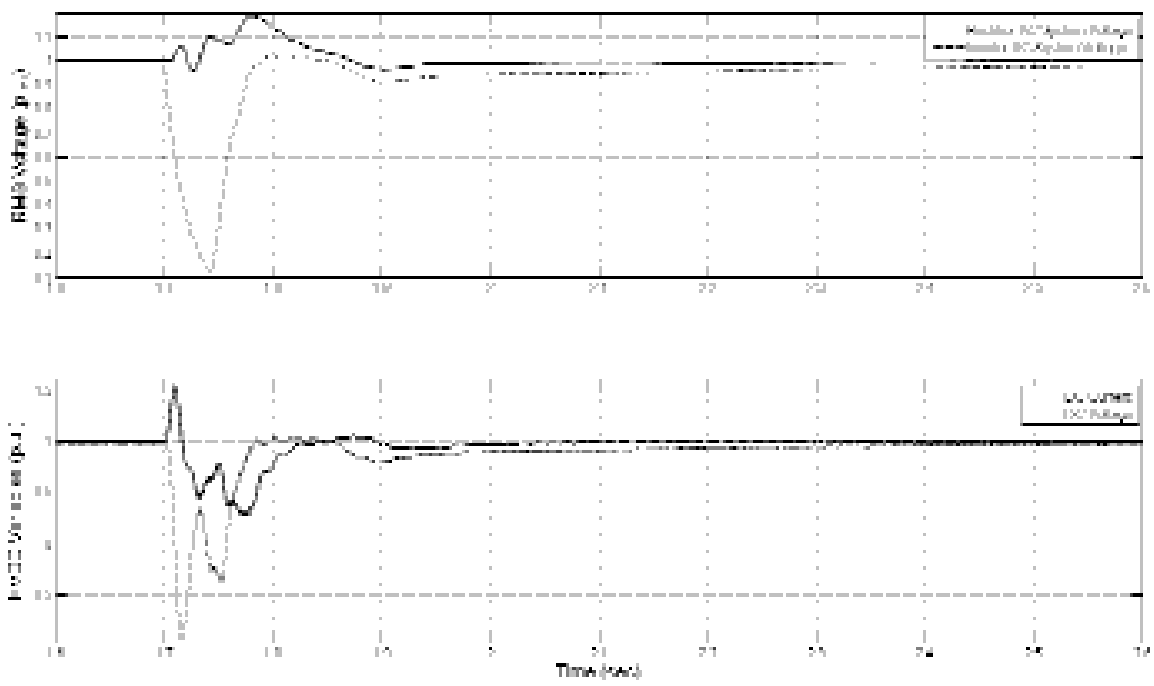

Figure 15: Tapping station characteristics during a rural AC system three-phase fault

rural AC system. The fault was applied at $1.7 \mathrm{sec}-$ onds and had duration of 0.04 seconds. The results of this simulation are shown in Figure 14. The results displayed in Figure 14 should be analyzed by comparing it with the results displayed in Figure 6. It should be noted that the tapping station did not impede the transient response of the HVDC system.

\section{Main inverter AC system fault}

A three-phase solidly earthed fault was applied to the inverter $\mathrm{AC}$ system near the inverter terminal, to determine the effect that a fault in the main inverter AC system will have on the tapping station and the rural AC system. The fault was applied at 1.7 seconds and had duration of 0.04 seconds. The results of this simulation are shown Figure 15. The results displayed in Figure 15 were analyzed by comparing it with the results displayed in Figure 7. It should be noted that the tapping station did not impede the transient response of the HVDC system.
HVDC transmission line fault

A solidly earthed fault was applied to the middle of the HVDC transmission line, to determine the effect that a HVDC transmission line fault will have on the tapping station and the rural $\mathrm{AC}$ system. The fault was applied at 1.7 seconds and had duration of 0.04 seconds. The results of this simulation are shown in Figure 16. The results displayed in Figure 16 should be analyzed by comparing it with the results displayed in Figure 8. It should be noted that the tapping station did not impede the transient response of the HVDC system.

\section{Conclusions}

The parallel-cascaded tapping station demonstrated that it has a negligible effect on the dynamic performance of the main HVDC link. The results obtained clearly indicate that the parallel-cascaded tapping station proves to be a viable solution to tapping small amounts of power from an HVDC trans- 

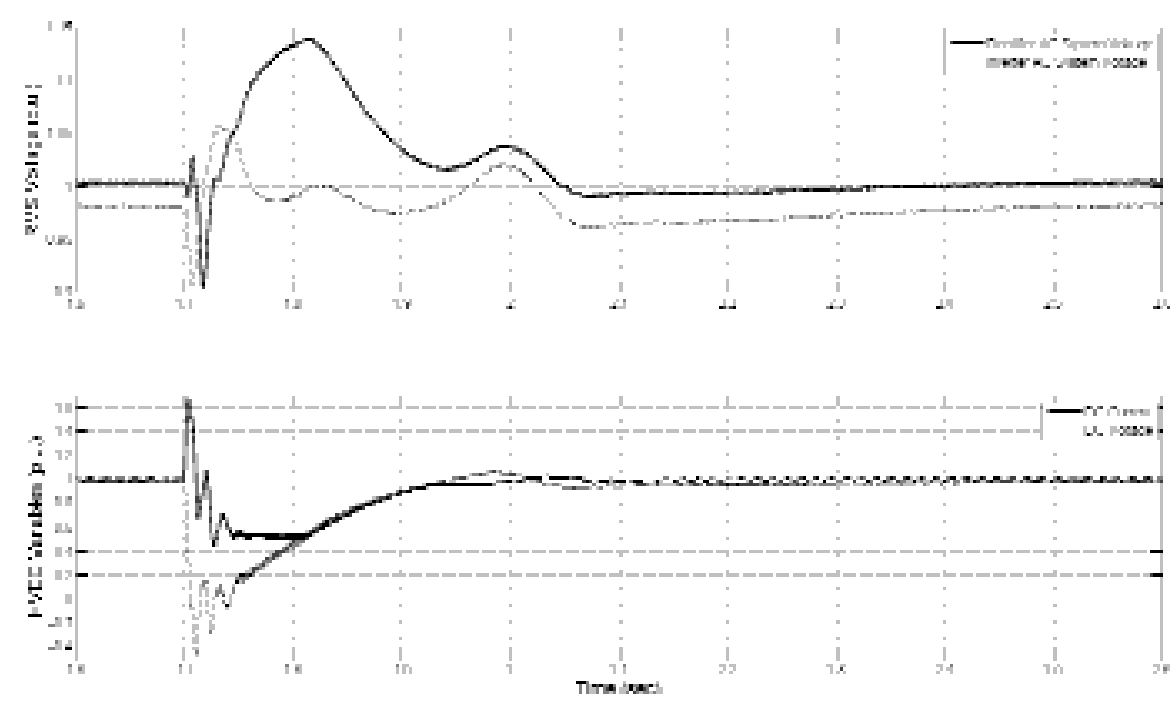

Figure 16: HVDC characteristics during a rectifier AC system three-phase fault

mission line. Therefore, HVDC transmission need not suffer a significant disadvantage compared to high voltage alternating current (HVAC) transmission, since power can now be tapped off from HVDC transmission lines. This paper has proved that it is theoretically feasible to tap off small amounts of power from HVDC transmission lines. This is a significant progress in HVDC technology. Especially considering that most HVDC transmission lines pass over many rural communities that have little or no access to electricity. Now, however, it may be possible to provide electricity to these communities from HVDC transmission lines.

\section{References}

Aghaebrahimi, M.R, \& Menzies, R.W (1997). Small power tapping from HVDC transmission systems: A novel approach. IEEE Trans. on Power Delivery 12(4):1698-1703.

Aghaebrahimi, M.R, \& Menzies, R.W (1998). A customized air-core transformer for a small power tapping station. IEEE Trans. on Power Delivery 13(14):1265-1270.

Aredes, M, et. al. (2001). HVDC tapping using softswitching techniques. Electrical Engineering Research Journal - Archiv fur Electrotechnik 83(1/2):33-40.

Aredes, M., et. al. (2002). A 500 kV Soft-Switching HVDC Tap. CIGRE 14-115.

Bahrman, M, et. al. (1995). Integration of small power taps into (existing) HVDC links. IEEE Trans. On Power Delivery 10(3):1699-1706.

Chetty, L., Ijumba N.M. \& Britten A.C. (2004). ParallelCascaded tapping station. Proc. of IEEE Int. Conf. Power System Technology. 1674-1878.

Ekstrom, A, \& Lamell, P. (1991). HVDC tapping station: Power tapping from a DC transmission line to a local
AC network. Proc. of IEE $5^{\text {th }}$ International Conf. on $A C$ and DC Power Transmission September: 126131.

Jovcic, D. (2009). Bidirectional High Power DC Transformer. IEEE Trans. on Power Delivery 24(4):22762283.

Khatib, H. (1998). Electrical power in developing countries. IEE Power Engineering Journal: 239-247.

Lamm, U, et. al., (1963). Some aspects of tapping HVDC systems. Direct Current 8(5).

Lima, A.G.G, et al., (1991). HVMDC: A new concept to feed small loads. Proc. of IEE $5^{\text {th }}$ International Conf. on AC and DC Power Transmission September: 120125.

Szechtman, M. et al., 1991. First Benchmark Model for HVDC Control Studies. Electra 135.

Turanli, H.M, et. al. (1989). A forced commutated inverter as a small series tap on a DC line. IEEE Trans. on Power Electronics 4(2):187-193.

Zhao, Z, \& Irvani, M.R. (1994). Application of GTO voltage source inverter for tapping HVDC power Proc. of IEE Conf. - Gen, Trans, Distri.141(1):19-26.

Rahman, H., \& Khan, B.H. (2008). Possibility of Power Tapping from Composite AC-DC Power Transmission Lines. IEEE Trans. on Power Delivery 23(3):14641471.

Received 27 September 2010; revised 19 September 2011 